\title{
Research on Improving the Welding Behaviour of Stainless Steels in the Field of Welded Constructions by Using Mechanical Vibrations
}

\author{
Bogdan Novac
}

\begin{abstract}
This paper presents a research that has been done on two types of stainless steels, one of Spanish origin and the other of Romanian origin. Both Spanish and Romanian stainless steels have been subjected to several tests, regarding the influence of vibrations on their mechanical properties and their welding behavior. The samples were made of welded stainless steels. They were subjected to a thermal hardening treatment at a temperature of 950 degrees, with a holding time of 4 hours in the presence of mechanical vibrations. Then comparative tests were performed on both stainless steels at: hardness, tensile test, resilience, microstructural analysis and determination of the longitudinal modulus of elasticity. The research has shown a reduction of the thermo-mechanically influenced area, which contributes to the achievement of a high quality welded joints.
\end{abstract}

Keywords - stainless steel, thermal treatment, vibrations, welding

\section{INTRODUCTION}

A newer direction in the field of welding constructions, is the application of mechanical vibrations, with relatively low frequencies, in the order of tens or hundreds of hertz. This frequency domain can be applied to the treatment of welding seams. The application of vibrations for the treatment of the welding seams, can be done during its solidification and cooling, or after complete cooling. By applying vibrations during the welding process, it was found that in addition to the direct effect of uniformity of the filler metal particles, which are deposited from the electrode, it also cancels the cavitation effect. During the welding operation, residual internal stresses are introduced in welded parts or welded constructions, which exceeding a certain value, are dangerous because they overlap over the stresses given by the construction requests. To reduce the value of these residual stresses, the parts are subjected to a stress relief operation. The stress relief operation can be done by overlapping vibrations over the heat treatment.

\section{EXPERIMENT DESCRIPTION}

From the analyzed steels, they were made 14 test samples. These samples were subjected to determinations of the accelerations and vibration parameters, hardness tests, tensile tests, resilience, determination of the longitudinal modulus of elasticity and 
microstructural analysis. They were used mechanical vibrations with a frequency of $75 \mathrm{~Hz}$ and powers of $750 \mathrm{~W}$. The specimens were previously subjected to hardening at a temperature of $9500 \mathrm{C}$, with a holding time of 4 hours. The steels used for this experimental research are: AISI 304 stainless steel of Spanish origin and Z 6 CNT 18.12B stainless steel of Romanian origin.

The chemical composition of the two steels is shown in Table 1:

Table. 1. Chemical composition of steels from Spain and Romania

\begin{tabular}{|c|c|c|c|c|c|c|c|c|}
\hline \multirow{2}{*}{ Steel type } & \multicolumn{7}{|c|}{ Chemical composition [\%] } \\
\cline { 2 - 10 } & $\mathrm{C}$ & $\mathrm{Si}$ & $\mathrm{Mn}$ & $\mathrm{P}$ & $\mathrm{S}$ & $\mathrm{Cr}$ & $\mathrm{Ni}$ & $\mathrm{Cu}$ \\
\hline Inox AISI304 & 0,045 & 0,027 & 2,34 & 0,026 & 0,013 & 29,01 & 8,02 & 0,363 \\
\hline Z 6 CNT 18.12B & 0,12 & 0,72 & 0,81 & 0,04 & 0,03 & 18,2 & 10,2 & - \\
\hline
\end{tabular}

On the two steels with the chemical composition presented in Table 1, were made determinations of accelerations and vibration parameters. For the hardening heat treatment of the steels have been made measurements with the oven fixed on the vibrating table for high speed, $\mathrm{n}=3420$ rotations / minute, with values presented in Table 2.

Table. 2. Determinations with the accelerometer fixed on the vibrating table connected to the excitation system - at speed $\mathrm{n}=3420$ rotations $/$ minute

\begin{tabular}{|c|c|c|c|c|}
\hline Harmonic order & Frequency $[\mathrm{Hz}]$ & $X\left[\mathrm{~m} / \mathrm{s}^{2}\right]$ & $Y\left[\mathrm{~m} / \mathrm{s}^{2}\right]$ & $Z\left[\mathrm{~m} / \mathrm{s}^{2}\right]$ \\
\hline 0,5 & 28,48 & 0,615 & 2,620 & 0,244 \\
\hline 1 & 56,95 & 5,350 & 7,090 & 51,400 \\
\hline 1,5 & 85,40 & 3,200 & 14,100 & 1,110 \\
\hline 2 & 113,9 & 3,170 & 13,100 & 14,500 \\
\hline 2,5 & 142,3 & 1,820 & 5,440 & 1,980 \\
\hline 3 & 170,9 & 1,720 & 3,480 & 16,700 \\
\hline 3,5 & 199,4 & 1,290 & 1,100 & 0,316 \\
\hline 4 & 227,8 & 1,410 & 3,470 & 7,050 \\
\hline 4,5 & 256,4 & 1,400 & 1,650 & 6,110 \\
\hline 5 & 284,8 & 1,680 & 1,870 & 7,070 \\
\hline 5,5 & 313,3 & 0,815 & 0,409 & 11,500 \\
\hline 6 & 341,7 & 3,650 & 0,379 & 5,920 \\
\hline 6,5 & 370,2 & 2,800 & 1,950 & 2,070 \\
\hline 7 & 398,7 & 0,943 & 1,710 & 12,500 \\
\hline 7,5 & 427,2 & 0,946 & 0,522 & 8,120 \\
\hline 8 & 455,7 & 2,090 & 1,240 & 11,800 \\
\hline 8,5 & 484,1 & 1,670 & 0,137 & 7,340 \\
\hline
\end{tabular}

\subsection{Hardness test of the two types of stainless steels}

Regarding the results of the hardness test to which the two steels were subjected, it shows that the Spanish stainless steel AISI 304, has higher hardness values compared to the Romanian stainless steel, Z 6 CNT 18.12B. This is due to a more careful elaboration of the Spanish steel and due to the lower level of impurities in its structure.

In the case of using mechanical vibrations, a hardness increase is observed for both steels. This increase in hardness is due to the influence of vibrations on the mechanisms of 
transformation of austenite to cooling in ferrite $\delta$. The high-speed cooling in water and the presence of vibrations, leads to significant structural hardening due to the formation of the $\sigma$ phase. Mechanical vibrations favor the arrangement of atoms in the structure. This fact can also be observed with the hardness results presented in Table 3 . The hardness in the Table 3 was measured in Brinell units.

Table. 3. The values of hardness obtained at hardening with and without vibration of the two stainless steels

\begin{tabular}{|c|c|c|c|c|c|c|c|c|c|}
\hline \multirow{2}{*}{ Steel type } & \multicolumn{4}{|c|}{ Without vibrations } & \multicolumn{3}{c|}{ With vibrations f=80 Hz, P=150 W } \\
\cline { 2 - 11 } & 1 & 2 & 3 & 4 & 1 & 2 & 3 & 4 & $\begin{array}{c}\text { Specialty } \\
\text { literature }\end{array}$ \\
\hline AISI304 & 314 & 310 & 317 & 308 & 318 & 320 & 329 & 340 & Max 340 \\
\hline Z 6 CNT 18.12B & 298 & 304 & 308 & 299 & 309 & 310 & 312 & 315 & Max 330 \\
\hline
\end{tabular}

\subsection{The tensile test of the welded joints made of the two types of stainless steels}

The results of tensile tests performed on welded joints of the two steels, Spanish AISI 304 and Romanian Z 6 CNT 18.12B, are presented in (Fig.1.a), for non-vibrated Spanish stainless steel and in (Fig.1.b), for vibrated Spanish steel. Also, in (Fig.2.a), for the nonvibrated Romanian stainless steel and in (Fig.2.b) for the vibrated Romanian stainless steel.

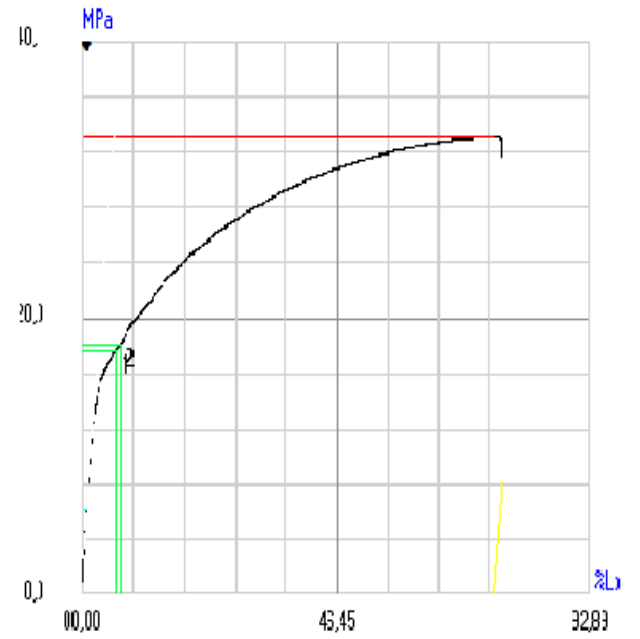

Fig.1. Tensile test variation graphics of th (a) Variation of the tensile strength of the welded joint of non-vibrated Spanish steel

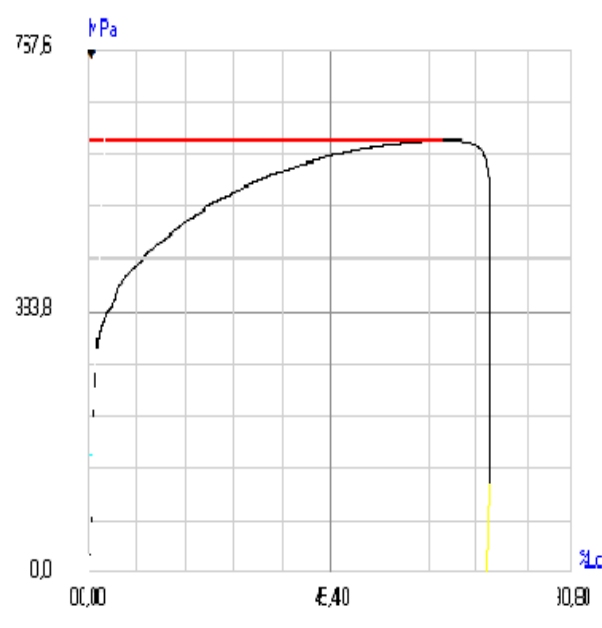

the welded joint of the Spanish stainless steel

(b) Variation of the tensile strength of the welded joint of vibrated Spanish stainless steel

It is observed an improvement in the mechanical properties of the welded joints, of both vibrated steels, by increasing the breaking strength, as well as the relative elongation.

Figure 1. (a), shows the graph of variation of the breaking force depending on elongation, for the welded joint made on AISI 304 stainless steel, of Spanish origin, nonvibrated. From this diagram you can see a very large increase in the elastic area compared to the plastic area, this is due to the amount of nickel in the steel structure that makes it more elastic. The material has a very short plastic area and the breakage is sudden. 
Figure 1. (b) shows the graph of variation of the breaking force depending on elongation for the welded joint made on vibrated steel of Spanish origin.

It is observed that in the case of vibration the maximum breaking force increases around $615 \mathrm{MPa}$ compared to $512 \mathrm{MPa}$, in the case of non-vibrated steel. Also, in this case there is an increase in the elastic area, but the plastic area is larger than that of the nonvibrated welded joint.
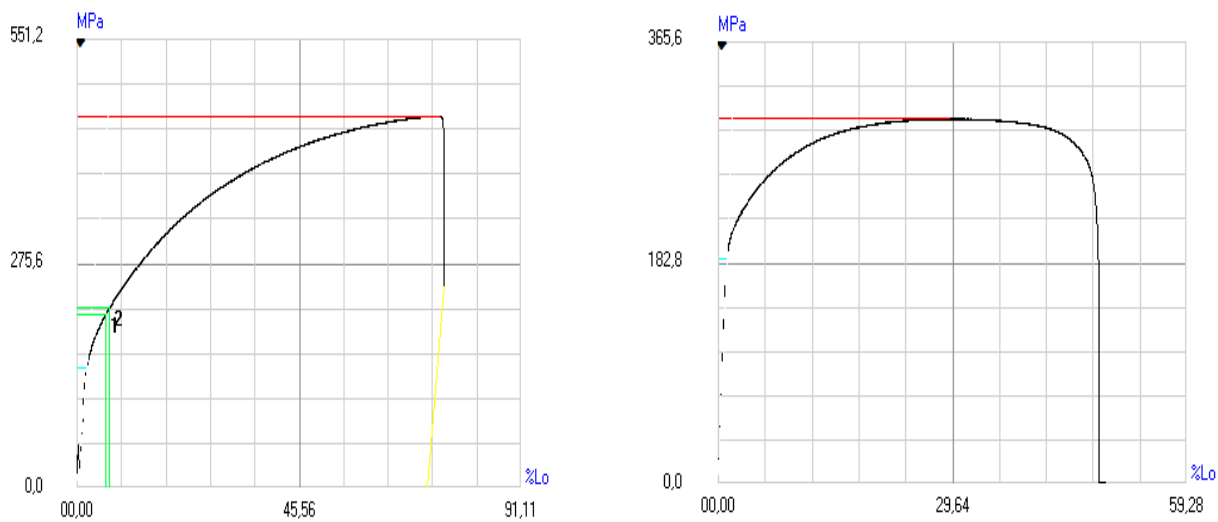

Fig.2. Tensile test variation graphics of the welded joint of the Romanian stainless steel

(a) Variation of the tensile strength of the welded joint of non-vibrated Romanian steel

(b) Variation of the tensile strength of the welded joint of vibrated Romanian stainless steel

Figure 2. (a) shows the variation graphic of the breaking force depending on the elongation for the welded joint made on steel Z 6 CNT 18.12B of Romanian origin, nonvibrated. In the same way as in the case of welded joint made on non-vibrated steel of Spanish origin, it is noticed a very developed elastic area, and the plastic deformation area is very small.

The breaking force in the case of this non-vibrating joint is $441 \mathrm{MPa}$, compared to $512 \mathrm{MPa}$ of the welded joint made on non-vibrated steel of Spanish origin.

In (Fig 2.b) is presented the graph of variation of the breaking force depending on the elongation, for the welded joint made on the steel of Romanian origin, vibrated. In this case it is observed that the elastic zone is much narrower than that of the welded joint made on steel of Spanish origin, increasing instead the plastic zone. This is explained, by the formation in the presence of vibrations, of ferrite $\delta$, in larger quantity. The difference in the chemical composition of the two steels also contributes to these differences. Both steels are part of the same alloy group, but with small differences in chemical composition.

The influence of hardening with and without vibrations on the longitudinal modulus of elasticity is shown in Table 4. Due to the increase of the hardening stress state, it takes place a decrease of the elastic modulus.

Table. 4. Variation of the modulus of elasticity at hardening with and without vibrations

\begin{tabular}{|c|c|c|c|c|c|c|c|c|}
\hline \multirow[t]{3}{*}{ Steel type } & \multicolumn{4}{|c|}{ Without Vibrations } & \multicolumn{4}{|c|}{ Vibrations $\mathrm{f}=80 \mathrm{~Hz}, \mathrm{P}=150 \mathrm{~W}$} \\
\hline & \multicolumn{8}{|c|}{ Modulus of elasticity $[\mathrm{MPa}] \times 10^{3}$} \\
\hline & 1 & 2 & 3 & 4 & 1 & 2 & 3 & 4 \\
\hline AISI304 & 2,148 & 2,183 & 2,198 & 2,152 & 2,156 & 2,124 & 2,189 & 2,132 \\
\hline Z 6 CNT 18.12B & 2,194 & 2,189 & 2,112 & 2,117 & 2,178 & 2,189 & 2,112 & 21215 \\
\hline
\end{tabular}


Resilience tests are performed on specimens having the dimensions and shape in (Fig.3).
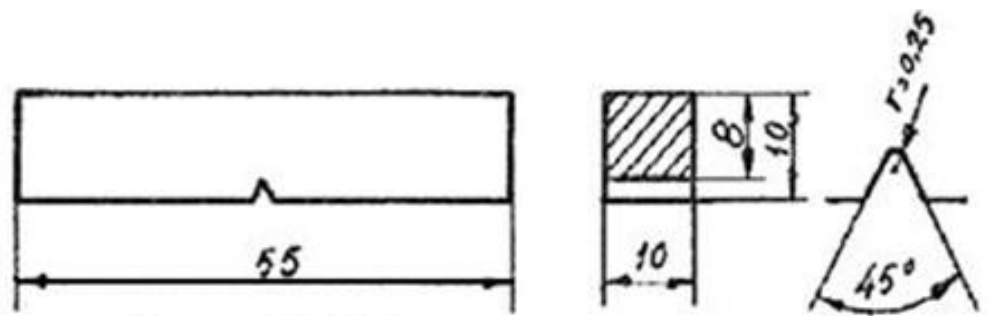

Fig.3. Dimensions of the test part for the resilience test

The tests were performed on a number of 8 specimens of each material, taking into account 4 of the most grouped values. There is a positive influence of vibrations on resilience as seen in Table 5.

Table. 5. Variation of resilience at hardening with and without vibration

\begin{tabular}{|c|c|c|c|c|c|c|c|c|}
\hline \multirow{3}{*}{ Steel type } & \multicolumn{4}{|c|}{ Without Vibrations } & \multicolumn{4}{|c|}{ Vibrations $\mathrm{f}=75 \mathrm{~Hz}, \mathrm{P}=750 \mathrm{~W}$} \\
\hline & \multicolumn{8}{|c|}{ Resilience KCV [J] } \\
\hline & 1 & 2 & 3 & 4 & 1 & 2 & 3 & 4 \\
\hline AISI304 & 29 & 30 & 32 & 31 & 38 & 36 & 39 & 40 \\
\hline Z 6 CNT 18.12B & 28 & 27 & 27 & 29 & 35 & 32 & 34 & 31 \\
\hline
\end{tabular}

\subsection{Microstructural analysis of both stainless steels}

Samples for microstructures are ground with a rotary device. The samples are then placed in a polymerized plastic mass using a machine shown in (Fig. 4).

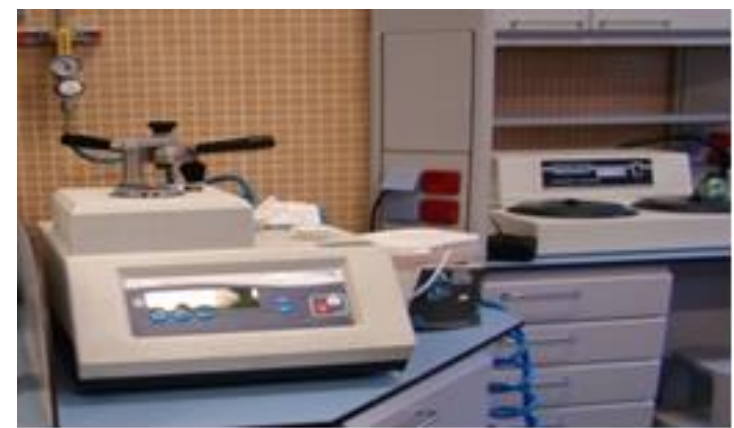

Fig.4. Machine for resin impregnation of samples for microscopic research

After grinding the samples are attacked with various reagents, depending on the materials used.

The microstructures obtained on the two materials after hardening, highlight a crystalline refinement in the presence of mechanical vibrations. This fact is observed from (Fig.5.a), for the vibrated AISI 304 stainless steel of Spanish origin, compared to the one from (Fig.5.b) for the non-vibrated. When applying vibrations, it is observed that the impurities at the grain boundary, are evenly distributed throughout the mass of the sample, which leads to an increase in the mechanical properties of the material. 


\section{sciendo}

68 Ovidius University Annals Series: Civil Engineering, Year 22, 2020

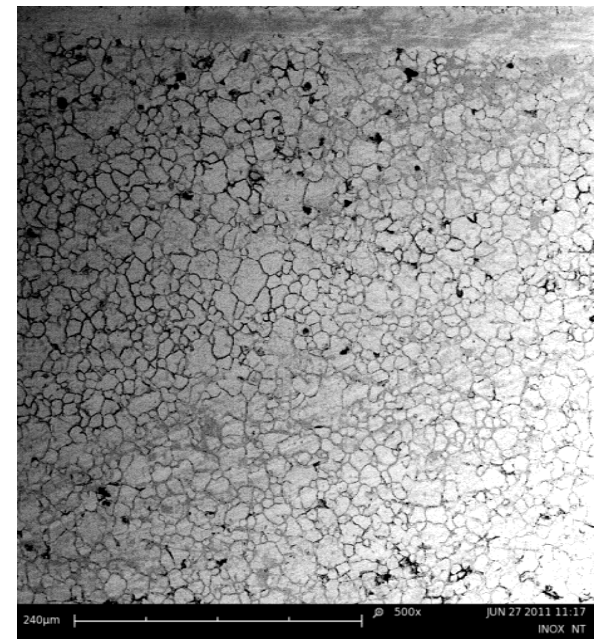

(a) Microstructure of Vibrated stainless steel AISI 304 Spain

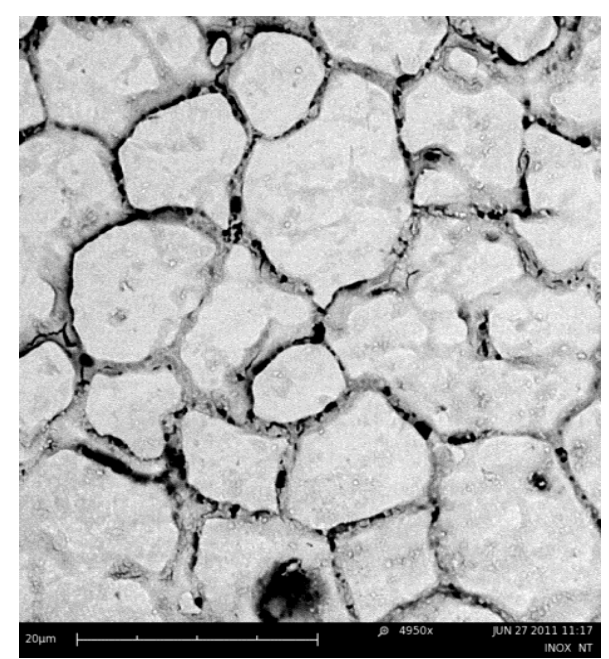

(c) Microstructure of Vibrated stainless steel Z 6 CNT 18.12B Romania

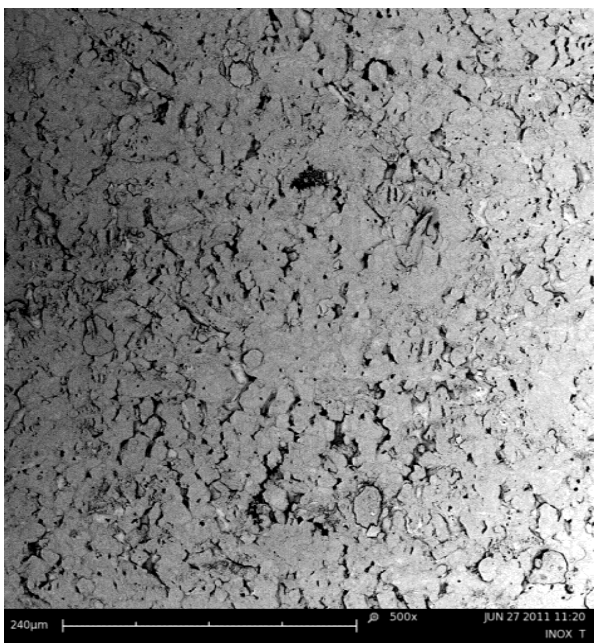

(b) Microstructure of Non-Vibrated stainless steel AISI 304 Spain

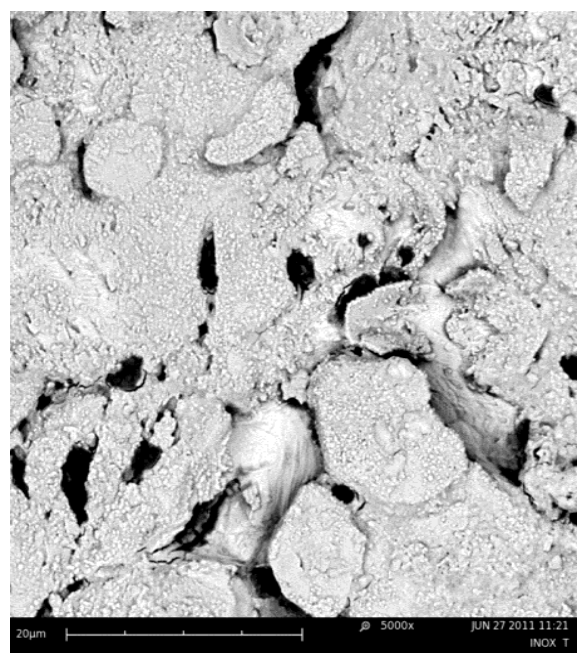

(d) Microstructure of Non-Vibrated stainless steel Z 6 CNT 18.12B Romania

Fig.5. Stainless steels microstructures, Romanian and Spanish

The same effect can be observed from (Fig.5.c), for the Romanian stainless steel, Z 6 CNT 18.12B vibrated, compared to the one from (Fig.5.d), non-vibrated. In the nonvibrated steel, a more pronounced contour of the crystals is observed, with chromium oxides placed at their limit, (Fig.5.c). In the case of vibrated steel, a penetration of oxides with crystals is observed, forming almost a common body, which leads to an increase in mechanical properties and corrosion resistance.

The microstructures obtained on hardened materials, with and without vibrations, highlight a finishing of the metallographic structure, in the presence of mechanical 
vibrations, which can be seen in (Fig.5.a) for the Spanish AISI 304 stainless steel, nonvibrated, compared to (Fig. 5.b) vibrated.

The same effect can be observed in (Fig.5.c), for the non-vibrated Romanian stainless steel, Z 6 CNT 18.12B, compared to the one in (Fig.5.d) vibrated.

\section{RESULTS AND SIGNIFICANCES}

These microstructures were analyzed using the FEI type electron microscope, (Fig.6.a) and they were processed using an electronic device for depositing gold on the breaking samples, (Fig.6.b).

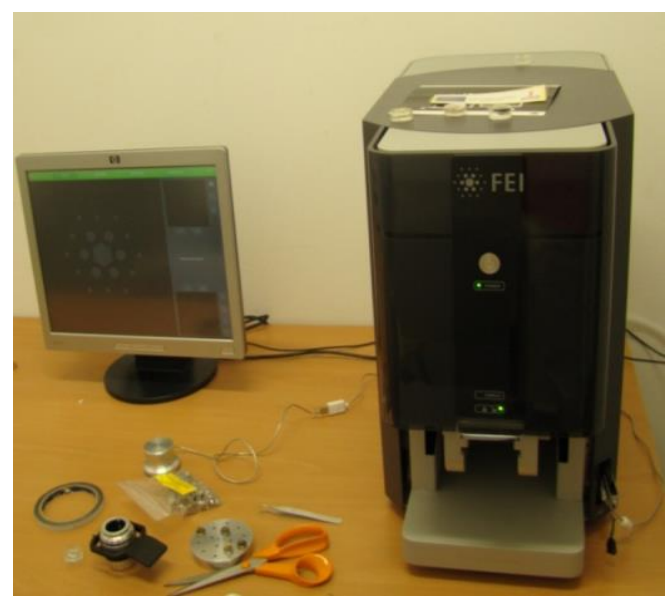

(a) FEI Electron Microscope

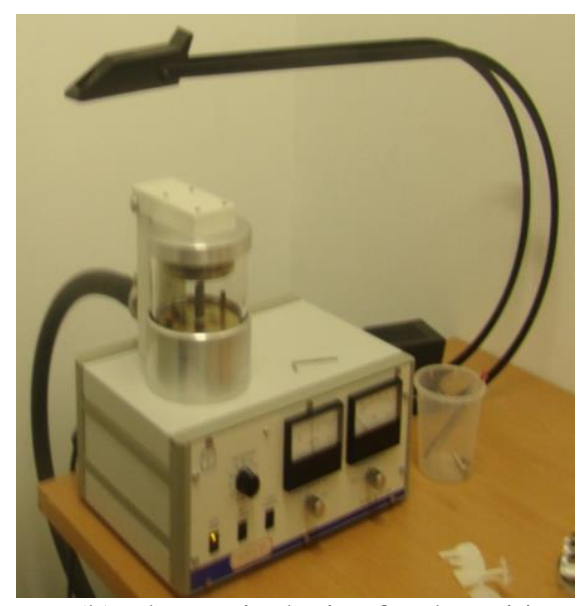

(b) Electronic device for depositing gold on breaking samples.

Fig.6. FEI Electron Microscope and the adjacent equipment

In this paper they were analyzed the mechanical properties of the metal deposited on steels of Spanish origin type AISI 304 and one of Romanian origin type Z CNT 18.12B. The obtained results confirm the fact that, the steel of Romanian origin has a welding behavior similar to that, of steel of Spanish origin. From the chemical analysis it is observed that the two steels have a similar composition only that the elaboration of the steel of Spanish origin is more careful, resulting in a structure with fewer defects. Tensile tests were performed using a Japanese tensile test machine type IHERTEST, and resilience tests were performed on $\mathrm{V}$-notched specimens.

The tests were performed on welded specimens, which were vibrated during welding and others without vibration during welding, in order to make comparisons between the two welding modes. When we were using mechanical vibration during the welding process, a finer structure was observed, due to the fact that, by vibration, several crystallization centers were formed and the stress state is lower. We can also see that the thermally influenced area is lower when welding in which vibrations were used. In conclusion, we can appreciate that welding in the presence of vibrations gives quality welded joints. Also, in the case of vibrated steel, an interpenetration of the oxides with the crystals is observed, forming almost a common body, which leads to the increase of the mechanical properties and the corrosion resistance of the welded joints. 


\section{CONCLUSION}

The paper presents the comparative welding behavior of two types of materials, one of Spanish origin and the other of Romanian origin. Following the researches, we can say that stainless steel of Romanian origin has a good behavior in welding, in the presence of vibrations, almost similar to that of stainless steel of Spanish origin. The difference consists in the more careful processing of Spanish steel. It can also be seen that the chemical composition of the two types of materials is approximately equal, and this made possible to compare their behavior in welding.

The equipment used in the research and the results of which were presented in this paper, is of Spanish origin.

\section{REFERENCES}

[1] Novac Bogdan, (2011), Contributions regarding the use of mechanical vibrations at the heat treatment and thermochemical treatment of the irons used in precision mechanics, Thesis, Transylvania University of Brasov. Romania

[2] Zara Adriana, Ene Emilian, Novac Bogdan, Ioan Giacomelli, (2009), Studies regarding heat treatments effectuated with modern technologies. World Scientific and Engineering Academy and Society (AFASES), Scientific Research and Education In The Air Force Brasov 20-22 May

[3] Novac Gheorghe, Novac Bogdan, (2009) Welding of boron and titanium micro alloyed steels. International Conference and Engineering, ISBN 973-635-454-7, February 26-28;

[4] Marin Cornel, (2008) Mechanical Vibrations. Applications. Problems. Ed.Bibliotheca [5] Safta Voicu, (2006) Technological and strength tests of welded or attached joints, Ed. Sudura Timișoara

Note:

Bogdan Novac- Ph.D. Engineer - Ovidius University of Constanta, Bd. Mamaia nr. 124, 900356 Constanta, Romania (corresponding author to provide phone: +40-725-227676; (e-mail: bogdannovac@yahoo.com) 